\title{
Students' Errors and Misconceptions about Operations of Fractions in an Indonesian Primary School
}

\author{
Ratnasari \\ Sampoerna University, Indonesia \\ Ratnasari.980410@gmail.com
}

\begin{abstract}
Fraction is one of the topics that is learned by students from primary, in secondary school and even college. When learning about fractions, sometimes students find difficulties that can trigger errors and misconceptions. This study was conducted to identify common students' errors and misconceptions about operations of fractions (i.e. addition, subtraction, multiplication, and division) in an Indonesian primary school. The study used a qualitative methodology and involved 4 participants (S1, S2, S3, and S4) from $6^{\text {th }}$ grade students from a classroom in a public primary school in South Jakarta. They were selected based on their scores on a test on operations of fraction (15 problems). The four participants who were chosen, each got 2, 4, 6, and 14 answers correct. The result of this study indicated that for these four students, some errors about fractions in their primary school were errors in computing the fractions and mistyping the solutions. Some of the misconceptions of fractions were related to fraction operations.
\end{abstract}

Keywords: Errors, fraction, misconceptions, primary school students.

\section{Introduction}

Researchers from Pakistan reported that mathematics is a difficult subject and results in low student achievement in terms of students score and mastering the content (Khalil \& Mohyuddin, 2016). Fractions are an important topic for students to learn since it relates to many other mathematical topics such as percentage, decimals, probability, and algebra (Aksoy \& Yazlik, 2017). Students have difficulties in developing fraction concepts, in using the notation to express fractions and in doing various operations of fractions such as addition, subtraction, multiplication, and division (Lortie-Forgues, Tian, \& Siegler, 2015). Those difficulties can lead students to make errors and develop misconceptions about fraction.

Errors are different from misconceptions. An example of an error is when students miscalculate because of carelessness (i.e. $6 \frac{4}{7}-2 \frac{2}{7}=\frac{46}{7}-\frac{16}{7}=\frac{24}{7}$ ). Errors are made not because of the lack of conceptual understanding but due to another reason. On the other hand, students' misconceptions are made when students do not fully grasp a mathematical concept. For example, when adding fractions with the same denominator, they not only add the numerators but they also add the denominators (i.e. $\frac{1}{4}+\frac{2}{4}=\frac{3}{8}$ ). Making errors and misconceptions are inevitable when learning something new, including with fractions. However, if not identified and then tackled student errors and misconceptions may lead to problems when students are learning further mathematical concepts. 
Students start learning fractions in elementary school. Before entering secondary school, usually, students are expected to solving problems fluently related to operations of fractions. Identifying students' errors and misconceptions is important, especially to inform mathematics teachers so that they can find strategies to help students improve their understandings about fractions.

The objective of this study was to identify some $6^{\text {th }}$ grade students' errors and misconceptions about operations of fractions, especially related to addition, subtraction, multiplication, and division of fractions. Additionally, this study will also explore students' reasons in making errors and misconceptions about operations of fractions.

\section{Literature Review}

This literature review will discuss the concept of fractions and its operations, and explain the difference between students' error and students' misconceptions.

\section{Fraction}

A fraction is a number that can be expressed in the form of $\frac{a}{b}$ which represent a part of a whole number or ratio between two numbers (Bennett, Burton, \& Nelson, 2012). A fraction contains of numerator and denominator.

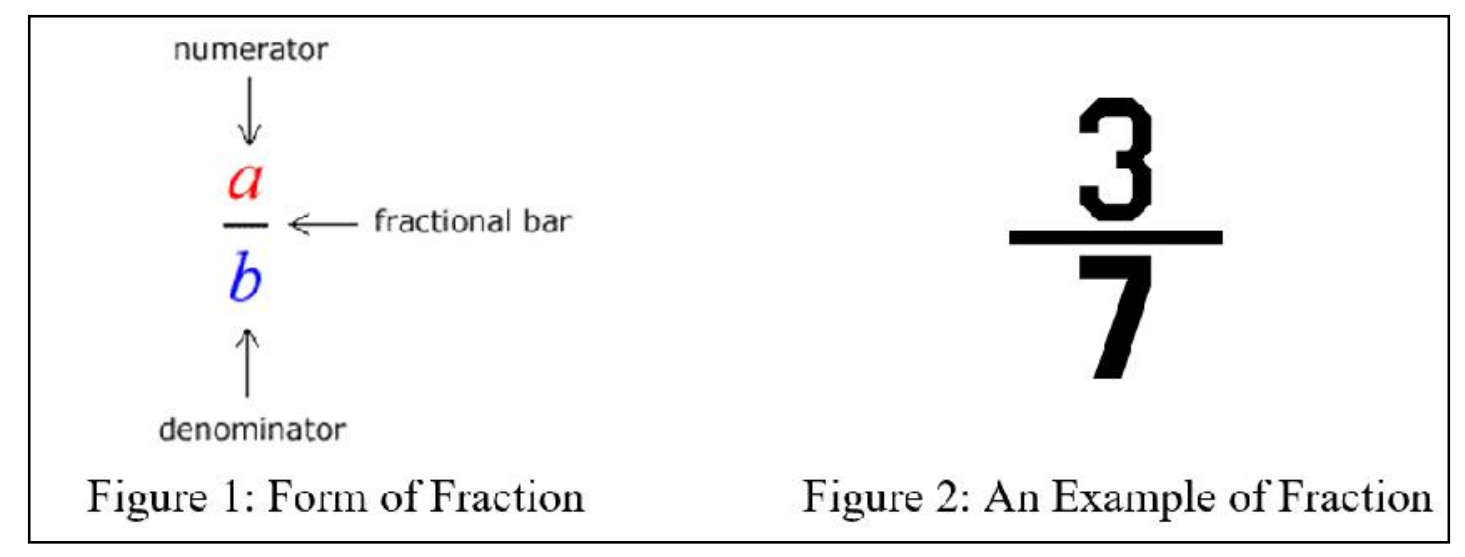

Figure 1. Form of fraction.

Figure 1 shows the form of a fraction, $a$ is the numerator of a fraction, which represent the number of part of the whole unit, and $b$ is the denominator of a fraction, which represent the total number of parts in the whole unit. For example, in Figure 2, illustrated is a fraction expression, 3 is a numerator and 7 is a denominator.

\section{Operations of Fraction}

\section{Addition and subtraction of fractions}

When adding or subtracting fractions, students will sometimes find some fractions that have the same denominators (like denominators) and have some fractions that different denominators (unlike denominator). When adding and subtracting fractions with like 
denominators, students just need to add the numerators and retain the denominator, for example, $\frac{1}{4}+\frac{2}{4}=\frac{3}{4}$ and $\frac{8}{9}-\frac{2}{9}=\frac{6}{9}$. In the first example they are adding one part of four parts to 2 parts of the same four parts so altogether they have 3 of the four parts. They need one more part to complete the whole unit.

However, if there are adding and subtracting fractions with unlike denominators, for example, $\frac{1}{2}+\frac{2}{4} \Rightarrow \frac{2}{4}+\frac{2}{4}=\frac{4}{4}$ and $\frac{4}{8}-\frac{1}{4} \Rightarrow \frac{4}{8}-\frac{2}{8}=\frac{2}{8}$. Notice that to add the fractions the students need to have two fractions with the same denominator by finding the least common multiple (LCM) of the denominators. In other words we can only add or subtract fractions where the whole units have the same number of parts. After finding the LCM of the denominators replace the fraction by having equal size parts (i.e. replace $\frac{1}{2}$ by $\frac{2}{4}$ because $\frac{1}{2}=\frac{2}{4}$ also replace $\frac{1}{4}$ by $\frac{2}{8}$ because of $\frac{1}{4}=\frac{2}{8}$ ). After the fractions have the same denominator just compute the numerators and retain the denominator.

\section{Multiplication}

The concept of multiplying fractions is different with adding and subtracting of fractions (Bennett, Burton, \& Nelson, 2012). There is multiplication of a whole number with a fraction for example, $5 \times \frac{1}{2}=\frac{5}{2}$. As well, there is multiplication of a fraction with a whole number for example, $\frac{1}{4} \times 7=\frac{7}{4}$.

There is also multiplication of any two fractions for example $\frac{1}{2} \times \frac{1}{2}=\frac{1}{4}$ and $\frac{1}{4} \times \frac{4}{7}=$ $\frac{4}{28}$. The skill of multiplying of fraction is to multiply the numerators and multiply the denominators. The concept of the first example is finding a half of a half as illustrated in the figure 1 below. The whole unit is a rectangle. It can be cut into two equal horizontal parts and shading one of the two equal parts is a half. We can repeat this process vertically. Thus, the whole shape is now divided into four equal parts and the intersection of the half with the half is one part of four which is a half of a half.

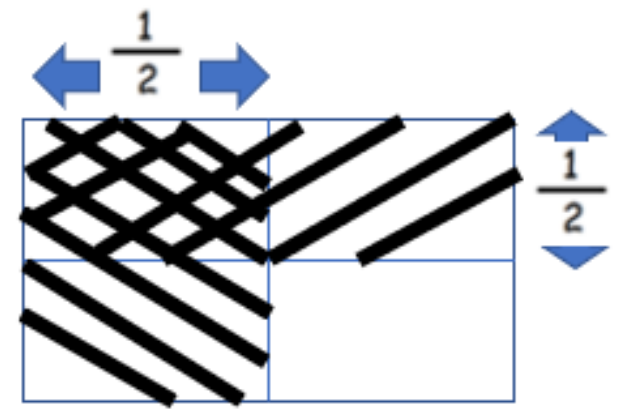

Figure 2. A half of a half.

In addition, it should be noticed that when multiplying fraction with a whole number for example 5, it can be written as a fraction: $\frac{5}{1}$ five lots of one whole. 


\section{Division}

The concept of dividing fraction is different to adding, subtracting, and multiplying fractions (Bennett, Burton, \& Nelson, 2012). One of common rules of dividing one fraction by another is to invert the divisor and multiply, for example, $\frac{1}{5} \div \frac{3}{4}=\frac{1}{5} \times \frac{4}{3}=\frac{4}{15}$. But this is not the concept of division.

Conceptual understanding is developed by using one meaning of division and moving from whole numbers to fractions. For example, 6 divided by two can mean how many lots of two we can make out of 6 . Then 6 divided by a half becomes if 6 whole units is divided into halves then how many lots of a half can we make out of 6 and the answer is 12 . Once the students develop this idea with easier fractions (6 divided by a third will give 18 thirds making 6 whole units), they can then be led to see that division by 2 is the same as multiplying by $\frac{1}{2}$, and that division by a half is the same as multiplying by $\frac{2}{1}$ and thus establishing a rule based upon understanding and not just memory.

\section{Errors about Operations of Fraction}

Spooner (2002) stated that an error happens because of carelessness, tor he misinterpretation of the question, and/or lack of knowledge of numbers.

$$
\text { (7) } 6 \frac{4}{7}-2 \frac{2}{7}=\frac{46}{7}-\frac{16}{7}=\frac{24}{7}
$$

Figure 3. Example of a S2 student's error in subtraction of fractions.

$$
\begin{aligned}
5 \frac{1}{2}: 3 \frac{2}{3} & =\frac{6}{2}: \frac{5}{3} \\
& =\frac{6}{2} \times \frac{3}{5} \\
& =\frac{18}{10}
\end{aligned}
$$

Figure 4. Example of a student's error in division of fractions. 
In figure 3 , a $6^{\text {th }}$ grade student made an error in computation when solving a problem about subtraction of fractions. (i.e. 46-16 should be equal to 30 but the student's answer was 24). In this case, the student may have been careless in solving the problem and is why it is classified as an error in this study.

Then, in figure 4, it shows that the student made an error in writing the mixed number (whole numbers and fractions) as an improper equivalent fraction (numerator is greater then the denominator). The student does not know how to work with mixed numbers. So the student adds the whole number to the numerator. It is interesting to note that student does know the rule of changing division to multiplying by the reciprocal. We cannot know if the student understands why. However, this study would classify the student's mistake as an error. The student may think that it can be solved by simplifying the numerator and denominator (Meilasari \& Jupri, 2017).

\section{Misconceptions}

Misconceptions are different to errors, and indicate a lack of understanding and a misuse of mathematical generalization (Khalil \& Mohyuddin, 2016). When students have a misconception about fractions, it means that they misinterpret the concept or the problem involving fractions and often use a rule that works with other types of numbers. For example, a student who doesn't have a strong conception of a fraction may just add the numerators and the denominators because this works for whole numbers.

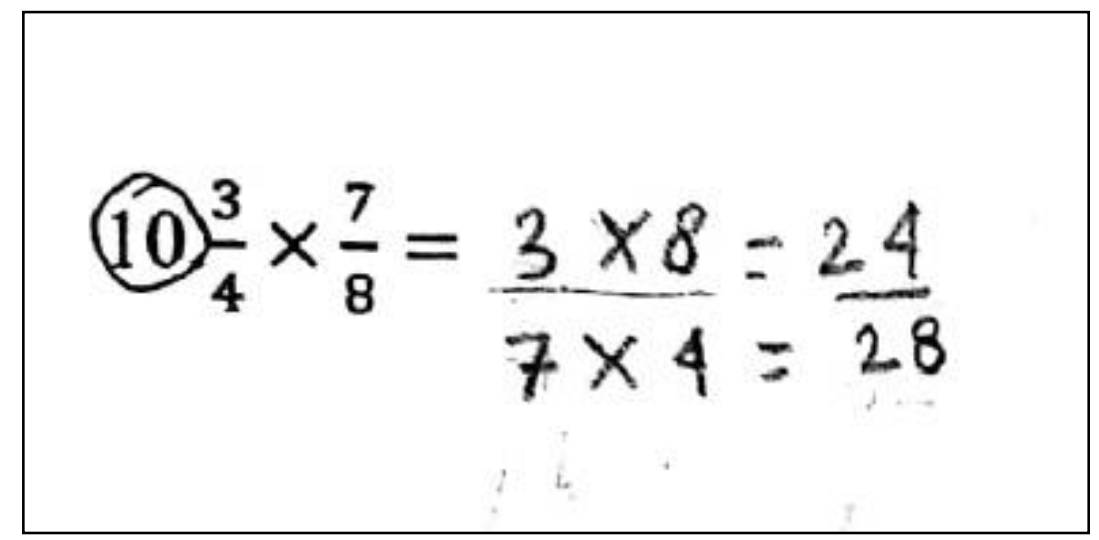

Figure 5. Example of student's misconception in multiplying fractions.

Figure 5 shows that the student has a misconception with multiplying the fractions. The student multiplies the numerator in the first fraction with the denominator in the second fraction and multiplies the numerator in the second fraction with the denominator in the first fraction or is treating the problem as cross multiplication. This case indicates that the student misapplied the rule of cross multiplication and also does not understand changing mixed numbers to improper fractions. 


$$
\begin{gathered}
\frac{5}{7} \times \frac{2}{7} \text { işleminin sonucu kaçtır? } \\
\frac{5}{7} \times \frac{2}{7}=\frac{10}{7} \\
\frac{2}{3} \times \frac{4}{9} \text { işlemnin sonucu kaçtır? } \\
\frac{3}{9} \times \frac{1}{9}=\frac{24}{9} \\
\frac{5}{7} \times \frac{2}{7} \text { işleminin sonucu kaçtır? } \\
\frac{5}{7} \times \frac{2}{7}=\frac{10}{7} \\
\frac{2}{3} \times \frac{4}{9} \text { ișlemnin sonucu kaçtır? } \\
\frac{6}{9} \times \frac{4}{9}=\frac{24}{9}
\end{gathered}
$$

Figure 6. Example of student's misconception in multiplying fractions.

Figure 6 is an example of a student's misconception where the student applied addition rule when solving a problem about multiplication of fractions. The student only multiplied the numerator but did not multiply the denominators. This is another case of using the wrong rule and similar findings were reported by Biber et al. (2013) in their study.

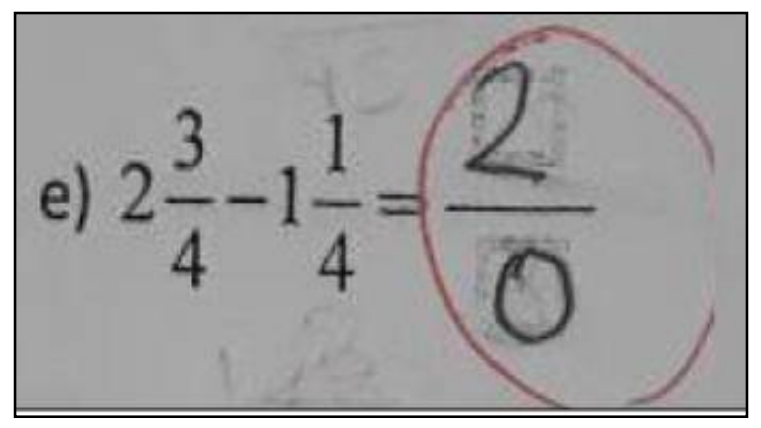

Figure 7. Example of student's misconception in subtracting fractions.

Figure 7 is an example of a student' misconception in subtracting fractions where a $5^{\text {th }}$ grade student got the result by not only subtracting the whole numbers but also subtracting the numerators and denominators. Similar misconceptions were reported in Nuri and Derya's study (2017). It indicates that that the students are memorizing rules with little understanding of the concepts. 


\section{Methodology}

The aim of this study was to identify some of the errors and misconceptions of Indonesian $6^{\text {th }}$ grade primary school students when solving operations with fraction problems. A test was designed to assess the students' skills and was given to all of the $6^{\text {th }}$ grade students in a primary school in Jakarta. The test results were analysed in general and four students work were chosen to be analysed in more detail and also to be interviewed.

\section{Participants}

The participants of this study were $6^{\text {th }}$ grade students from a public primary school in Jakarta. The school was chosen because the location was near the domicile of the researcher. Therefore, doing the research in that school was feasible. The focus was on $6^{\text {th }}$ grade students. According to the Kurikulum Tingkat Satuan Pendidikan (KTSP) national curriculum, which the school uses for teaching mathematics, all of students should have learned about fractions since $3^{\text {rd }}$ grade. Then, they should have learned about operations of fractions since $5^{\text {th }}$ grade. So this study will involve students who have been taught the operations with fractions, and will examine the performance of the $6^{\text {th }}$ grade students on a fractions test.

In the school, there were twenty-nine $6^{\text {th }}$ grade students. All of them were given an essay test about operations of fractions that consisted of 15 problems. The test was scored based on whether or not the students were able to find the correct answer. Four students were chosen to become the interview subjects of this study. The first student (S1), was the one with the lowest score with 2 out of 15 answers correct. The second (S2) and third (S3) were students whose score was near the average, where S2 got 4 and S3 got 6 out of 15 answers correct. The fourth student (S4) was the student with the highest score who got 14 out of 15 answers correct.

\section{Instruments}

In order to examine some errors and misconception of the Indonesian $6^{\text {th }}$ grade primary school students, a test about operations of fractions was given to all of twenty-nine $6^{\text {th }}$ graders in the school. Students were asked to write their steps in solving each problem and also their final solutions. The test was a purely arithmetic test and there were no word problems. The following table is the 15 problems in the test.

\section{Procedures}

To identify the students' errors and misconceptions, the data of the four participants' test answers were analysed through coding. The researcher compared all of the participants' answers and identified the errors and misconceptions.

The participants were also interviewed by the researcher one-by-one, both for validation (of their answers) and to explore their reasons why they were making errors and the nature of their misconceptions. Participants had to explain why they answered their questions the way they did. The test instrument is shown in Table 1. 
Table 1

The Test Problems about Operations of Fractions

\begin{tabular}{|c|c|c|}
\hline Number & Type of problem & Problem \\
\hline 1 & Addition of simple fractions with common denominators. & $\frac{2}{13}+\frac{4}{13}=$ \\
\hline 2 & Addition of simple fractions with unlike denominators. & $\frac{7}{3}-\frac{2}{9}=$ \\
\hline 3 & $\begin{array}{l}\text { Subtraction of simple fractions with common } \\
\text { denominators. }\end{array}$ & $\frac{6}{7}-\frac{2}{7}=$ \\
\hline 4 & Subtraction of simple fractions with unlike denominators. & $\frac{3}{4}-\frac{1}{2}=$ \\
\hline 5 & Addition of mixed fractions with common denominators. & $2 \frac{4}{7}+6 \frac{1}{7}=$ \\
\hline 6 & Addition of mixed fractions with unlike denominators. & $4 \frac{3}{5}+2 \frac{1}{15}=$ \\
\hline 7 & Subtraction of mixed fractions with common denominators. & $6 \frac{4}{7}-2 \frac{2}{7}=$ \\
\hline 8 & Subtraction of mixed fractions with unlike denominators. & $8 \frac{4}{8}-2 \frac{1}{4}=$ \\
\hline 9 & $\begin{array}{l}\text { Multiplication of simple fractions with common } \\
\text { denominators. }\end{array}$ & $\frac{2}{7} \times \frac{1}{7}=$ \\
\hline 10 & $\begin{array}{l}\text { Multiplication of simple fractions with unlike } \\
\text { denominators. }\end{array}$ & $\frac{3}{4} \times \frac{7}{8}=$ \\
\hline 11 & Division of simple fractions with common denominators. & $\frac{1}{3} \div \frac{2}{3}=$ \\
\hline 12 & Division of simple fractions with unlike denominators. & $\frac{5}{6} \div \frac{3}{2}=$ \\
\hline 13 & $\begin{array}{l}\text { Multiplication of mixed fractions with common } \\
\text { denominators. }\end{array}$ & $1 \frac{1}{9} \times 2 \frac{3}{9}=$ \\
\hline 14 & Multiplication of mixed fractions with unlike denominators. & $2 \frac{2}{3} \times 5 \frac{1}{5}=$ \\
\hline 15 & Division of mixed fractions with unlike denominators. & $8 \frac{1}{2} \div 4 \frac{3}{4}=$ \\
\hline
\end{tabular}

\section{Results}

Based on the analysis of the four students' work and their interview results, in this study, the researcher found that students made errors with the computations when solving the 15 problems and there was evidence of misconceptions regarding to operations of fractions, which resulted from a lack of understanding. 


\section{Students' errors in writing the solution and in the computations}

$$
\text { (7) } \left.6 \frac{4}{7}-2 \frac{2}{7}=\left(\frac{20}{7}\right)=9 \frac{2}{7}\right)
$$

Figure 8. S2 made an error in writing the working of the solution but got the correct answer.

$$
\text { (15.8 } \begin{aligned}
\frac{1}{2} \div 4 \frac{3}{4}=\frac{17}{81}=\frac{19}{4}=\frac{17}{8} \times \frac{4}{19} & =\frac{68}{152} \\
& =\frac{34}{76} \\
& =\frac{17}{38}
\end{aligned}
$$

Figure 9. S4 make a careless error in writing the solution of dividing fractions.

The two figures above 8 and 9 were considered as students' errors because the students mistyped in writing the solutions. Figure 7 shows that S2 wrote the correct final result but made a mistake when writing the first step as $\frac{20}{7}$ whereas the result should be $\frac{30}{7}=$ $4 \frac{2}{7}$. This was confirmed by the interview, where $\mathrm{S} 2$ stated:

$\mathrm{mmm}$ I forget to write $\frac{46}{7}-\frac{16}{7}$ so, the result should be $=\frac{30}{7}$ ehhh but here I wrote $=\frac{20}{7} . \mathrm{I}$ mistyped the result, ka sorry (S2).

Then, S4 also made an error in writing the solution of the problem as figure 8 shows. It is different from S2 as she mistyped the first step but she got the correct final answer whereas S4 mistyped at the start of the process which led to the incorrect solution. S4 mistyped in writing the denominator and so computed the incorrect fraction with another fraction then the result was incorrect. The error was also confirmed by $\mathrm{S} 4$ in the interview result, which mentioned that:

wadduuhh I wrote $\frac{17}{8}$ but it should be $17 / 2$ because the denominator is 2 . Why I wrote this yah? Ahahahahha I wrote it unconsciously.

So these errors are based on carelessness of due to the stress of the test, whereas misconceptions are a more serious problems because they involve misunderstandings and will take more time to overcome. 


\section{Students' misconception in adding fractions with unlike denominators}

$$
\text { (2) } \frac{7}{3}+\frac{2}{9}=\frac{7+2}{27+27}=\frac{9}{54}
$$

Figure 10. Evidence in question 2 of S3's misconception.

$$
\text { (2) } \frac{7}{3}+\frac{2}{9}=\frac{7}{3}+\frac{2}{9}=\frac{9}{9}
$$

Figure 11. Evidence in question 2 of S2's misconception.

$$
\text { (2.) } \frac{7}{3}+\frac{2}{9}=\frac{9}{12}
$$

Figure 12. Evidence in question 2 of S1's misconception.

The figures above show that 3 out of 4 of the $6^{\text {th }}$ grade students have misconceptions about the concept of adding fractions with unlike denominators. It is evidence that they have memorized some rule rather than understanding what is happening when adding fractions.

Based on the analysis (Figure 10) and the interview, S3 knows that when adding fractions with unlike denominators, she has to make the fractions have a common denominator. However, she does not know that after she found the common denominator, she had to replace the fractions with equivalent fractions and then just compute the numerators and retain the common denominator.

In Figure 11, S2 knows that when adding two fractions she must add the numerators but doesn't appear to understand the role of the denominators. She just computed the numerator and did not find the equivalent fractions, which must have a common denominator.

As it is shown in figure 12, S1 just adds the numerators and the denominators. In the interview, S1 stated that when there is addition fractions with unlike denominator you just sum up numerators and denominators. It means that the student considers the numerator and denominator as being separate and uses whole number rules to get an answer. This is clear 
evidence that the student has no understanding of fraction notation and so will struggle to answer questions using the operations with fractions.

\section{Students' misconception in subtracting fractions with unlike denominators}

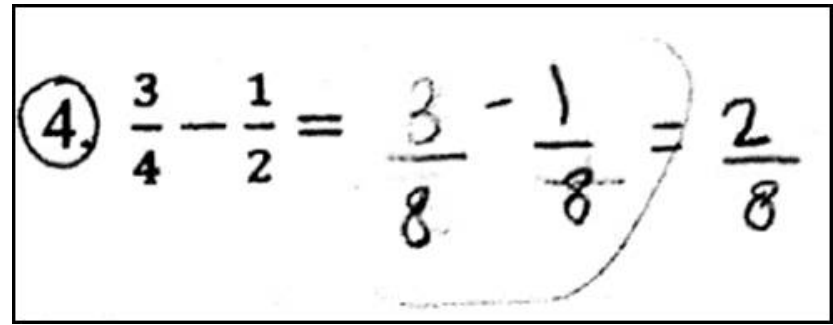

Figure 13. S3's answer for problem 4.

$$
\text { (4) } \frac{3}{4}-\frac{1}{2}=\frac{3}{4}-\frac{1}{2}=\frac{2}{4}
$$

Figure 14. S2's answer for problem 4.

$$
\text { (4.) } \frac{3}{4}-\frac{1}{2}=\frac{2}{2}
$$

Figure 15. S1's answer for problem 4

The findings in problem number 4 about subtracting fraction with unlike denominators: Again 3 out of four students think that the concept of subtracting fractions with unlike denominator also the same with adding fraction with unlike denominator concept where both $\mathrm{S} 2$ and $\mathrm{S} 1$ tried to solve this problem as if adding fractions with unlike denominators. However, S3 knew she needed common denominators but did not find the equivalent fractions. She knew she could subtract the denominators with common denominators so her problem lies with understanding equivalent fractions.

\section{Students' misconception in multiplying fractions}

$$
\text { (9) } \frac{2}{7} \times \frac{1}{7}=\frac{2}{7}
$$

Figure 16. S3's answer for problem 9. 
In this study, the researcher found that often students multiplying fractions with common denominators as shown in figure 16, a student (i.e. S3) will just multiply the numerators and retain the denominator as in addition of fractions with a common denominator. So that the student's misapplication of the rule of addition for multiplication fractions. In the interviewed, S3 said:

multiply the numerators, since the denominator of the fractions already the same, I just multiply 2 and 1 then I have $\frac{20}{7}(\mathrm{~S} 3)$.

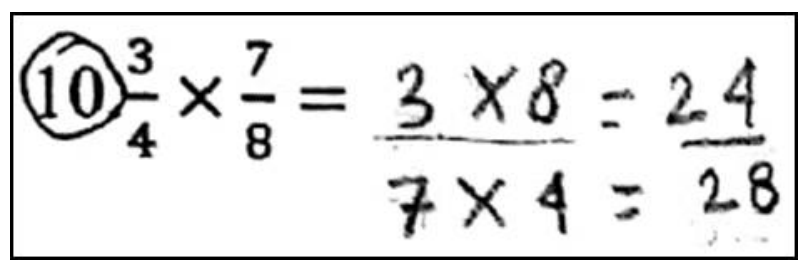

Figure 17. S3's answer for problem 10.

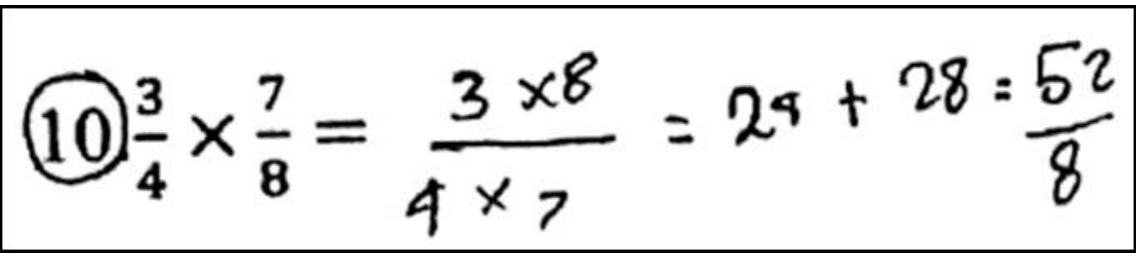

Figure 18. S2's answer for problem 10.

Moreover, figure 17 and 18 shows that with multiplication of fractions with unlike denominators, two out of the four $6^{\text {th }}$ graders mistake the question for cross multiplication. As it is shown in figure 16, that to solve the problem, S3 applied a cross multiplication rule. Then, in figure 78, S2 also used cross multiplication and added the result of multiplications and put them over 8 . In the interview, S2 said:

when there is multiplication fractions, we should multiply numerator in the first fraction with denominator in the second fraction, then also multiply denominator in the first fraction with numerator in the second fraction, ka. And we should sum up the result of multiplication since in this problem the LCM of 4 and 8 is 8 so just write 8 as a denominator in this solution (S2).

\section{Students' misconceptions in dividing fractions}

$$
\text { (11) } \frac{1}{3} \div \frac{2}{3}=\frac{1}{3}: \frac{2}{3}=\frac{2}{3}
$$

Figure 19. S3 make a misconception in dividing fractions with like denominators. 


$$
\text { (11) } \frac{1}{3} \div \frac{2}{3}=\frac{2}{3}
$$

Figure 20. S2's misconception with dividing fractions with like denominators.

$$
\text { (11). } \frac{1}{3} \div \frac{2}{3}=\frac{2}{3}
$$

Figure 21. S1's misconception with dividing fractions with like denominators.

In Figure 19, 20, and 21, students appear to think that to solve division of fractions problem number 11 with like denominators, you just divide 2 by 1 in the reverse of the division sign and retain the denominator because the denominators are already the same. Further proof that they have memorized rules without understanding.

$$
\text { (11) } \frac{1}{3} \div \frac{2}{3}=\frac{1}{3} \times \frac{3}{2}=\frac{3}{6}
$$

Figure 22. S4 correctly dividing fractions with like denominators but did not simplify.

This study found that there is only one student (i.e. S4, who got 14 out of 15 correct answers) could find the correct answer and do the correct step in finding the solution of the problem number 11 involving division of fractions with like denominators as is shown in Figure 22.

$$
\text { (15) } \begin{aligned}
8 \frac{1}{2} \div 4 \frac{3}{4} & =\frac{1}{2} \times 4 \frac{4}{3}=8 \frac{3}{6} \times \\
4 \frac{8}{6} & =32 \frac{24}{6}
\end{aligned}
$$

Figure 23. S3's answer in solving division fraction with unlike denominator.

In figure 23, S3 inverts the denominator of the second fraction and changes the operation of this fraction from division into multiplication. Then, S3 tried to make the denominators the same. Then S3 multiplied the whole numbers, and multiplied the numerators and the denominator was retained because it had the same denominator. 


\section{Discussion}

Based on the findings from this study, it indicated that most of the interview students, 3 out of four $6^{\text {th }}$ graders had errors and misconceptions about fractions, especially in the operations with fractions. Students were making errors in computation and errors in writing the solution. These errors, it is argued, happen because the students involved are either careless or are stressed by the test. Spooner (2002) mentioned reported errors happen because of carelessness, lack of number knowledge, or misinterpreting the problems.

According to the analysis of students' misconception in adding and subtracting fractions with unlike denominators. It shows that two of the four students in this study thought that the concept of this operation is to make the denominator the same but the way they computed the result was different. For example, the student S2 made the denominator to be the same, then added or subtracted the numerators and retained the denominator. The students changed the fractions but they were not equivalent fractions. It appeared that the student was following a rule that had been memorized but now had forgotten all the steps.

The interview students also revealed misconceptions in multiplication and division of fractions. In multiplying fractions, two out of four $6^{\text {th }}$ grade students applied a cross multiplication rule to find the solution. This appears unique as they have a similar interpretation, which is to solve multiplication of fraction problems by applying cross multiplication. Yet in the next step, they had a different way to find the solution.

Based on the finding, only one of the four $6^{\text {th }}$ graders understood the concept of dividing fractions. While 3 out of 4 students demonstrated that they did not understand.

Thus, the result of this study indicates that most students still make errors and have misconceptions about fractions, especially with operations of fractions even they are $6^{\text {th }}$ grade students. To prevent and address the errors and misconceptions when students learn fractions, teachers need to find strategies that might be helpful for teacher to address and prevent the errors and misconceptions about fractions such as using concrete and pictorial models to represent the concept of fractions and equivalent fractions (Hui, Hoe, \& Lee, 2017; Reys, 2009).

\section{Conclusion}

The main objective of this study was to identify some students' errors and misconception with operations of fractions. Due to the sample limitations of this study, the findings can only apply to the students in the sample and cannot be regarded as representing a wider group of Indonesia students. However, the findings can be of interest to teachers and educators in making comparisons with their own situation.

So, based on the findings and discussion in this study, it can be concluded that with this sample of four students, when $6^{\text {th }}$ grade students solve a problem involving operations of fractions (i.e. addition, subtraction, multiplication, and division) they are likely to either make errors or have some serious misconceptions. There are two types of errors that were found in this study, namely errors in computation and error in writing the solution of the problem. Moreover, there are a number of misconceptions that the $6^{\text {th }}$ grade students revealed dealing 
with adding, subtracting fractions with unlike denominator, in multiplying and division of fractions. The common misuse of rules is symptomatic of students memorizing without understanding. The reasons behind this result could be a future research study. For example are teachers teaching too quickly for students to understand? If so then students are just trying to memorize without understanding and this is often forgotten. Why are teachers going too quickly? Is it because of final examinations and they want time to revise? These are questions that further research could help to answer.

Since errors and misconceptions not only distract students learning process but also can result in low students' achievement. It is suggested that it will be better if teachers identify students' errors and misconceptions earlier and try to find strategies to address the errors and misconceptions.

\section{References}

Aksoy, N. C. and Yazlik, D. O. (2017). Student Errors in Fractions and Possible Causes of These Errors. Journal of Education and Training Studies, 219. doi:doi:10.11114/jets.v5i11.2679

Bennet, A. B., Burton, L. J, and Nelson, L. T. (2012). Integers and Fractions. In Mattson, S.K ( $9^{\text {th }}$ Eds) Mathematics for Elementary Teachers: A Conceptual Approach (pp.309 - 319). New York: McGraww-Hill.

Biber, A. C., Tuna, A., and Aktas, O. (2013). Students' misconceptions of fractions and its effect on solving fractions. Trakya University Journal of Education, 152-162. Retrieved from http://dergipark.gov.tr/download/article-file/200350

Maelasari, E. \& Jupri (2017). Analysis of Student Errors. Journal of Physics: Conference Series. doi:doi:10.1088/1742-6596/812/1/012033

Khalil, R and Mohyuddin, R. H. (2016, June). Misconceptions of Students in Learning Mathematics at Primary Level. Bulletin Educational Research, 133-162.

Lortie-Forgues, H., Tian, J., and Siegler, R. S. (2015, September 26). Why is learning fraction and decimal arithmetic so difficult? Retrieved from http://dx.doi.org/10.1016/j.dr.2015.07.008

Spooner, M. (2002). Errors and misconceptions in maths at key stage 2. Working towards a successful SATs. London: David Fulton Publishers.

Hui, C. S., Hoe, L. N., and Lee, K. P. (2017). Teaching and Learning with ConcretePictorial-Abstract Sequence - A Proposed Model. Retrieved from http://math.nie.edu.sg/ame/matheduc/tme/tmeV17_1/paper1.pdf

Reys, R. E. (2009). Helping children learn mathematics (9th ed.). Hoboken, NJ: John Wiley $\&$ Sons. 